\title{
Endondontie
}

\section{Gut Ding will Weile haben}

Am 1. September 2015 erhielt der Wurzelkanalzement N2 eine erneute Zulassung unter dem neuen Namen Endo N2. Der Zement ist allein oder als Sealer in Verbindung mit Guttapercha-Stiften verwendbar und hat eine antimikrobielle Wirkung, die mit der allmählichen Aushärtung erlischt. Seit über 50 Jahren gehört die Sargenti Methode in vielen Zahnarztpraxen

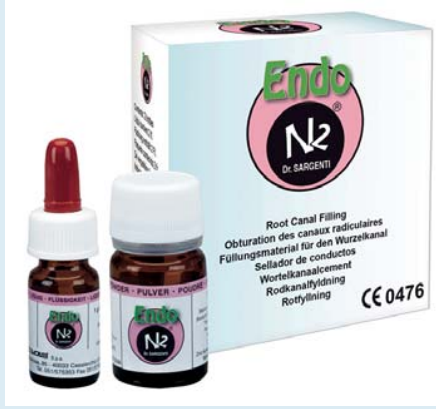
zum Alltag.Der Ze-

ment ist ab sofort bestellbar im Dentalfachhandel oder bei Hager \& Werken. Endo N2 ist als Pulver, als Liquid oder als Set erhältlich.

Nach einer Pressemitteilung des

Hager \& Werken GmbH \& Co. KG, Duisburg

www.gesundes-implantat.de 